\title{
Identification and genetic analysis of EMS- mutagenized wheat mutants conferring lesion-mimic premature aging
}

Weiwei Kong ${ }^{1 \dagger}$, Liming Wang ${ }^{1 *+} \mathbb{D}$, Pei Cao ${ }^{2}$, Xingfeng $\mathrm{Li}^{3}$, Jingjing $\mathrm{Ji}^{1}$, Puhui Dong ${ }^{1}$, Xuefang Yan ${ }^{1}$, Chunping Wang ${ }^{1}$, Honggang Wang $^{3}$ and Jiaqiang Sun ${ }^{4^{*}}$

\begin{abstract}
Background: Lesion-mimic and premature aging (Impa) mutant Impal was identified from the ethyl methane sulfonate (EMS) mutant library in the bread wheat variety Keda 527 (KD527) background. To reveal the genetic basis of Impa1 mutant, phenotypic observations and analyses of chlorophyll content and photosynthesis were carried out in Impa 1, KD527 and their $F_{1}$ and $F_{2}$ derivatives. Further, bulked segregation analysis (BSA) in combination with a $660 \mathrm{~K} \mathrm{SNP}$ array were conducted on the $\mathrm{F}_{2}$ segregation population of Impa1/Chinese spring (CS) to locate the Impa1 gene.

Results: Most agronomic traits of Impa1 were similar to those of KD527 before lesion-like spots appeared. Genetic analysis indicated that the $\mathrm{F}_{1}$ plants from the crossing of Impa1 and KD527 exhibited the Impa phenotype and the $F_{2}$ progenies showed a segregation of normal (wild type, WT) and Impa, with the ratios of Impa: $W T=124: 36\left(X^{2}=\right.$ $1.008<=3.841$ ), indicating that Impa is a dominant mutation. The combination of BSA and the SNP array analysis of CS, Impal and Impar/CS F $\mathrm{F}_{2}$ T pool (50 plants) and Impa pool (50 plants) showed that polymorphic SNPs were enriched on chromosome $5 \mathrm{~A}$, within a region of $30-40 \mathrm{Mb}$, indicating that the wheat premature aging gene $\mathrm{Lmpa} 1$ was probably located on the short arm of chromosome $5 \mathrm{~A}$.

Conclusions: EMS-mutagenized mutant Impa1 deriving from elite wheat line KD527 conferred Impa. Lmpa phenotype of Impal mutant is controlled by a single dominant allele designated as Lmpa1, which affected wheat growth and development and reduced the thousand grain weight (tgw) of single plant in wheat. The gene $\mathrm{Lmpa} 1$ was tentatively located within the region of 30-40 Mb near to the short arm of chromosome 5A.
\end{abstract}

Keywords: Wheat, Impa1, Mutant, Chromosomal location

\footnotetext{
*Correspondence: Imwang1@163.com; sunjiaqiang@caas.cn

†Weiwei Kong and Liming Wang contributed equally to this work.

'Agronomy College, Henan University of Science and Technology, Luoyang 471023, Henan, China

${ }^{4}$ Institute of Crop Science, Chinese Academy of Agricultural Sciences, Beijing 10081, China

Full list of author information is available at the end of the article
}

(c) The Author(s). 2020 Open Access This article is licensed under a Creative Commons Attribution 4.0 International License, which permits use, sharing, adaptation, distribution and reproduction in any medium or format, as long as you give appropriate credit to the original author(s) and the source, provide a link to the Creative Commons licence, and indicate if changes were made. The images or other third party material in this article are included in the article's Creative Commons licence, unless indicated otherwise in a credit line to the material. If material is not included in the article's Creative Commons licence and your intended use is not permitted by statutory regulation or exceeds the permitted use, you will need to obtain permission directly from the copyright holder. To view a copy of this licence, visit http://creativecommons.org/licenses/by/4.0/ The Creative Commons Public Domain Dedication waiver (http://creativecommons.org/publicdomain/zero/1.0/) applies to the data made available in this article, unless otherwise stated in a credit line to the data. 


\section{Background}

Lesion-like mutants $(\mathrm{llm})$ can spontaneously form spots on leaves, sheaths, or whole plants without significant damage, stress, or external pathogen infection [1]. The phenotype of $\mathrm{llm}$ is very similar to the hypersensitivity response (programmed cell death, PCD) after infection with pathogens [2]. Lesion-like spots (lls) formation is controlled by specific genes and/or affected by certain environmental conditions. They may be mostly caused by cell death and partially be correlated with pigment accumulation [3]. Previous researches [4] indicated that the mechanism of the lesion formation is very complicated because they may be controlled by genes related to disease resistance, regulation of death, and basic metabolic enzymes. Both signal molecules in plant defense to diseases and in environmental responses also play important role on the formation of lls.

In recent years, ethyl methane sulfonate (EMS) has been widely used to induce mutants with different agronomic traits in crops because it has the advantages of higher point mutation, fewer chromosomal aberrations, and easier screening of mutants over other methods [5-8]. EMS is a useful tool for improving particular agronomic traits, breeding new varieties, and screening elite germplasms [9]. Mutant germplasms induced by EMS can be effectively used to mine new genes, promote functional genomics studies, and accelerate breeding program [10].

To date, $l l m$ have been reported in corn [11], Arabidopsis [12], barley [13], and rice [14]. In recent years, wheat $l l s$ have been gradually found. For example, Geng [15] mapped a new wheat spot-like mutation gene $\operatorname{lm} 3$. $\mathrm{Li}$ et al. [16] found that wheat white spot mutation $I 30$ was controlled by a pair of recessive nuclear genes which were located on wheat chromosome $6 \mathrm{D}$ by using of BSA method and $660 \mathrm{~K}$ SNP array technology. Yao et al. [17] obtained a LLM from the crossing between normal parents Yanzhan 1 and Zaosui 30 and the LLM was controlled by two recessive genes named $\operatorname{lm} 1$ and $\operatorname{lm} 2$.M66 [18], C591 (M8) [19], AIM9 [20], Ning7840 [21], HLP [22], LF2010 [23] and other wheat lesion mutants have also been reported.

Senescence is the final stage of plant development and an active process of extracting nutrients from old tissues. Premature aging can shorten the growth stage of crops, cause premature senility of functional organs earlier before grain filling [24], thus affecting crop yield and quality [25]. Many reports and in-depth studies on premature senescence in rice have been documented to date [26]. The gene of leaf premature senescence mutant wss 1 was located within $1200 \mathrm{~kb}$ near the centromere region of the long arm of chromosome 11 in rice [27]. Signs of senescence began to appear in the rice premature senescence mutant es 4 in about 60 days, due to the loss of function of the calcium-dependent protein kinase
OsCPK12 [28]. The 3-bp deletion in the gene of WLS5 also leads to premature senescence in rice [29]. The early senescence mutations esl2 [30], esl3 [31], esl4 [32], esl5 [33], and esl6 [34] selected by the Rice Research Institute of Southwest University by EMS mutation were controlled by mononuclear genes. Xiao et al. [35] located the mutant gene of premature aging mutant $z s$ in the $600 \mathrm{~kb}$ region on the short arm of rice chromosome 12 . The rice premature senescence gene PLS2 was preliminarily determined to encode a glycosyltransferase by Wang et al. [36]. In recent years, wheat premature senescence has also been reported. Two additive QTLs on chromosomes 3A and 3B detected by Wei [37] were related to wheat early senescence indicators and six physiological traits related to premature senescence. An additive QTL controlling the flag leaf senescence was located between markers gwm526 and gwm382 on the long arm of chromosome 2A [38]. The leaf senescence gene els1 was located on the chromosome of 2BS by bulked segregant RNA sequencing (BSR-Seq) method in common wheat [39]. T. Kajimura [40] used homologous cloning to obtain genes related to wheat aging, TaSAG1TaSAG9, TaSAG1, TaSAG3, TaSAG4, and TaSAG5 are genes related to amino acid metabolism, TaSAG7 and TaSAG8 are genes related to fatty acid metabolism, and TaSAG9 is related to sugar and genes related to ribose metabolism, TaSAG2 and TaSAG6 are genes used to encode seed proteins.

This study reports the isolation of wheat lesion-like premature senescence mutants by EMS mutagenesis, and the genetic analysis of these mutants. The chromosomal localization of the premature aging gene was performed by the analysis of the segregating populations. This study generated germplasm resource for future cloning of new genes related to early senescence and exploring the regulatory mechanism of early senescence in wheat. It also laid a foundation for breeding new wheat varieties conferring resistance to premature senescence.

\section{Results}

\section{Generation and identification of Impa mutant}

Multi-year agronomy comprehensive identification was used to select the lmpa mutant from the $\mathrm{M}_{6}$ generation induced by EMS in KD527 (Fig. 1a, c), which was named lmpal (Fig. 1b, d). The agronomic identifications were conducted in KD527 and lmpa1 and shown in Table 1. As can be seen from Table 1 and Fig. 1, the agronomic characters of lmpa1 is similar to KD527 in plant height $(p h)$, flag leaf length $(f l l)$, ear length $(e l)$, number of grains per ear (ngpe) and other agronomic traits. The process of the formation of lmpa in lmpal was observed throughout its whole growth period. Impa1 grows normally at seedling stage. After flag leaf picking, it appeared $l l s$ before senescence. Its leaves present some 

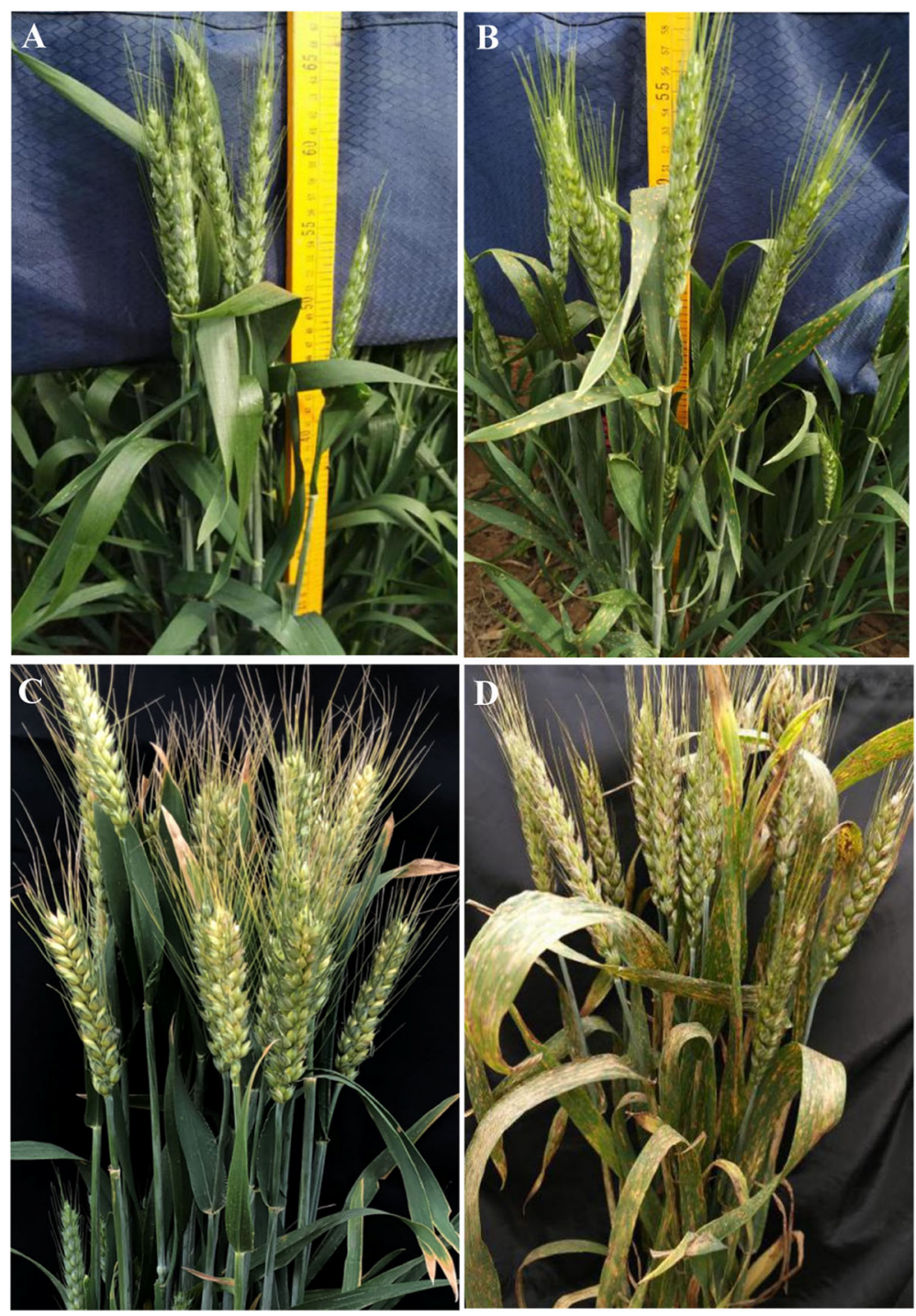

Fig. 1 Phenotypes of the WT KD527 (a, c) and the mutants Impal (b, d) during late heading $(\mathbf{a}, \mathbf{b})$ and mid-late filling stage (c, d), respectively. Note: a: WT KD527 grows normally during late heading stage; $\mathbf{b}$ : A small amount of brown spots can be found on the leaves of mutant Impa1 at the late heading stage; c: KD527 grows normally at mid-late filling stage stage; $\mathbf{d}$ : L/s expand quickly to the leaves, stems and even spikes of Impaland premature aging appears during mid-late filling stage

Table 1 Statistical analysis of Impa traits in mutants and their hybrid progenies

\begin{tabular}{|c|c|c|c|c|c|c|c|c|}
\hline \multirow{2}{*}{$\begin{array}{l}\text { Material / } \\
\text { Combination }\end{array}$} & \multirow[t]{2}{*}{ Generations } & \multicolumn{3}{|c|}{ Phenotype } & \multirow{2}{*}{$\begin{array}{l}\text { Separation } \\
\text { ratio }\end{array}$} & \multirow{2}{*}{$\begin{array}{l}\text { Theoretical } \\
\text { ratio }\end{array}$} & \multirow[t]{2}{*}{$x^{2}$} & \multirow[t]{2}{*}{$P$} \\
\hline & & Impa & WT & Total & & & & \\
\hline KD527 & & I & WT & All & 1 & I & I & I \\
\hline Impal & & Impa & / & All & / & / & / & / \\
\hline \multirow[t]{2}{*}{ Impa1/KD527 } & $\mathrm{F}_{1}$ & 10 & 0 & 10 & / & / & & \\
\hline & $\mathrm{F}_{2}$ & 124 & 36 & 160 & 3.44 & $120: 40$ & 1.008 & 0.465 \\
\hline
\end{tabular}

Note: $\mathrm{df}=1 ; \mathrm{X}_{0.05}^{2}=3.841, \mathrm{X}_{0.01}^{2}=6.635$ 

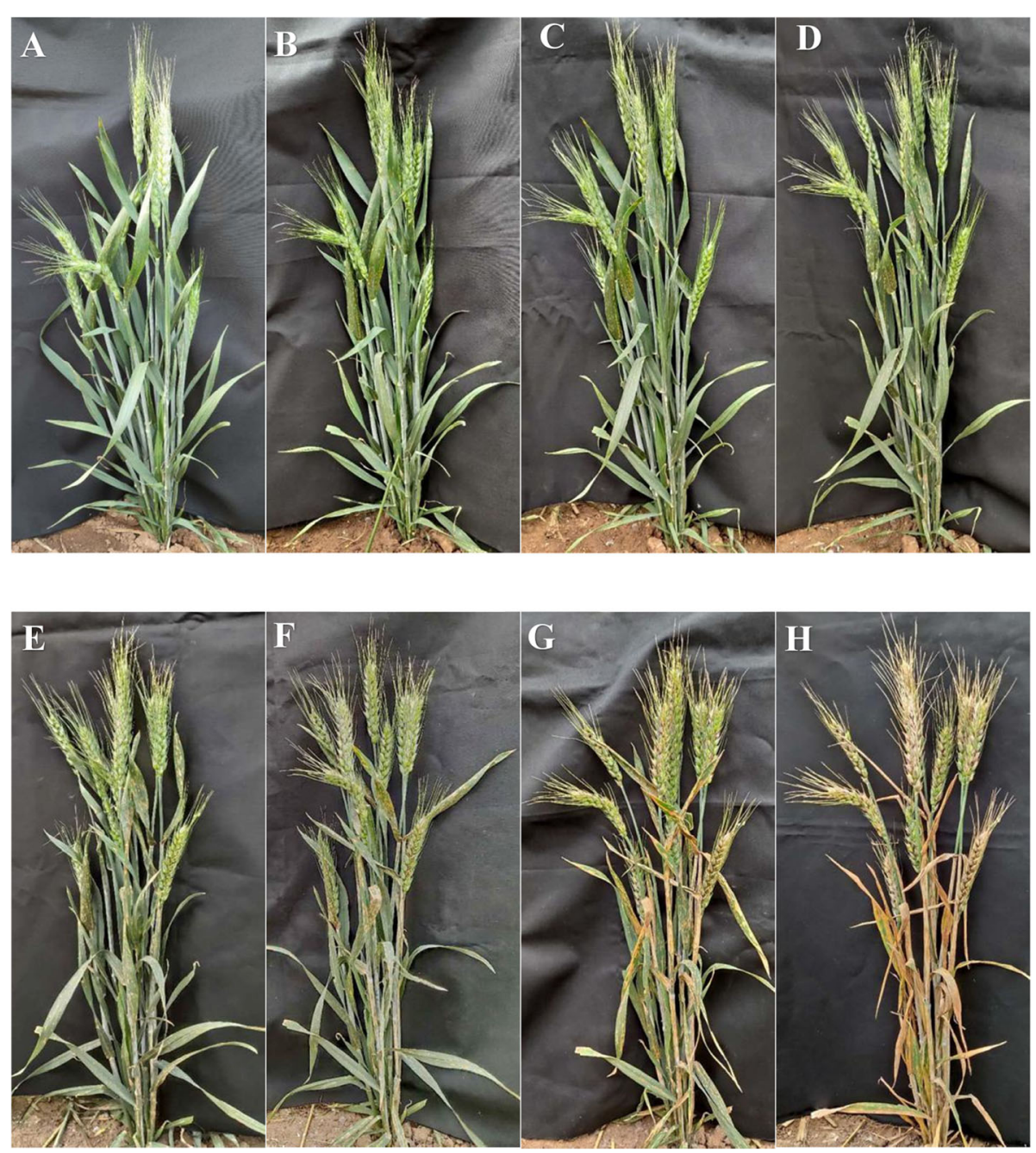

Fig. 2 Formation, expansion and spread of Impa of Impal mutant at different growth stages after heading in 2019. Note: a: Impa1 single plants have not been found I/s on 23th April; $\mathbf{b}: I m p a 1$ leaves have a small amount of brown spots on 24th April; $\mathbf{c}$ : Impa1 leaves have a significant increase in brown spots on 26th April; $\mathbf{d}$ : A large number of brown-yellow spots spread on the stem of Impal on 30th April; e: Ils on the leaf spread to the leaf sheath, and a few brown-yellow spots appeared on the stem of Impar on 4th May; $\mathbf{f}$ :The brown and yellow spots on the stems continued to increase, and a few brown and yellow spots appeared on the spikes of Impa1 on 16th May; g: Impal leaves began to dry, and the brown and yellow spots on the spikes continued to increase on 20th May; $\mathbf{h}$ : Impal leaves and stems were withered, part spikes were drying up on 24th May

Table 2 Agronomic traits of KD527, Impal and their hybrids

\begin{tabular}{|c|c|c|c|c|c|c|c|}
\hline Materials & & $\mathrm{ph}(\mathrm{cm})$ & $\mathrm{fll}(\mathrm{cm})$ & el $(\mathrm{cm})$ & ngpe & $\operatorname{tg} w(g)$ & ypp (g) \\
\hline KD527 & & $58.3 \pm 2.9^{a}$ & $17.4 \pm 0.4^{a}$ & $9.7 \pm 0.5^{a}$ & $62.7^{a}$ & $54.45^{a}$ & $27.31^{a}$ \\
\hline Impal & & $50.3 \pm 3.3^{c}$ & $17.2 \pm 0.6^{a b}$ & $8.8 \pm 0.6^{c}$ & $52.5^{c}$ & $42.17^{c}$ & $17.71^{c}$ \\
\hline \multirow[t]{3}{*}{ Impa1/KD527 } & $F_{1}$ & $55.9 \pm 4.5^{a b}$ & $16.8 \pm 0.7^{b}$ & $9.5 \pm 0.5^{\mathrm{ab}}$ & $57^{b}$ & $44.67^{b c}$ & $20.37^{b c}$ \\
\hline & $\mathrm{F}_{2} / \mathrm{mpa}$ & $52.6 \pm 2.1 \mathrm{bc}$ & $16 \pm 0.5 c$ & $9.1 \pm 0.7^{b c}$ & $57.51^{b}$ & $43.50^{c}$ & $20.01^{b c}$ \\
\hline & $F_{2} W T$ & $54.6 \pm 2.2^{b}$ & $16.6 \pm 0.2^{b}$ & $9.4 \pm 0.4^{a b}$ & $59.3^{a b}$ & $49.17^{b}$ & $23.33^{b}$ \\
\hline
\end{tabular}




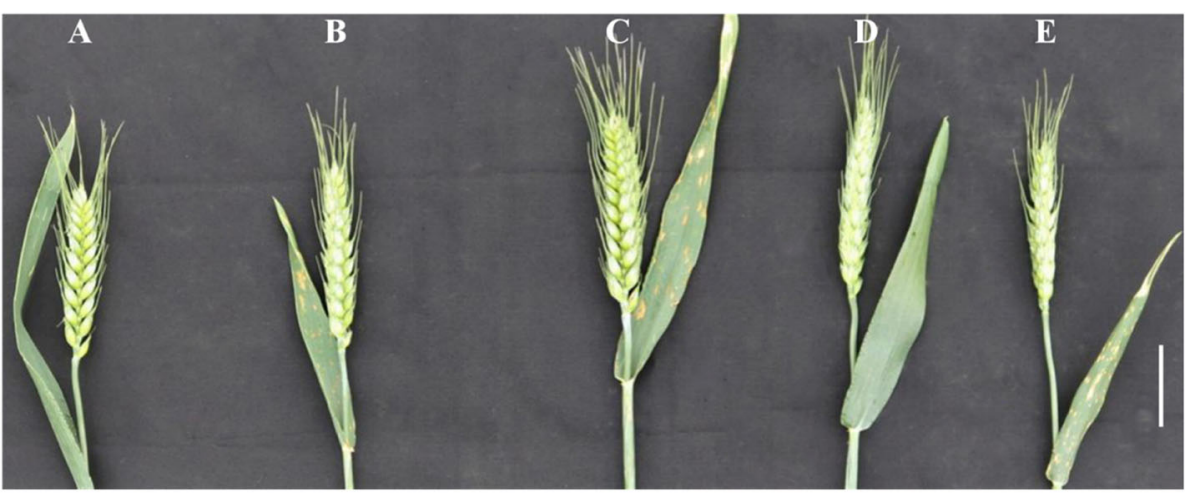

(a)
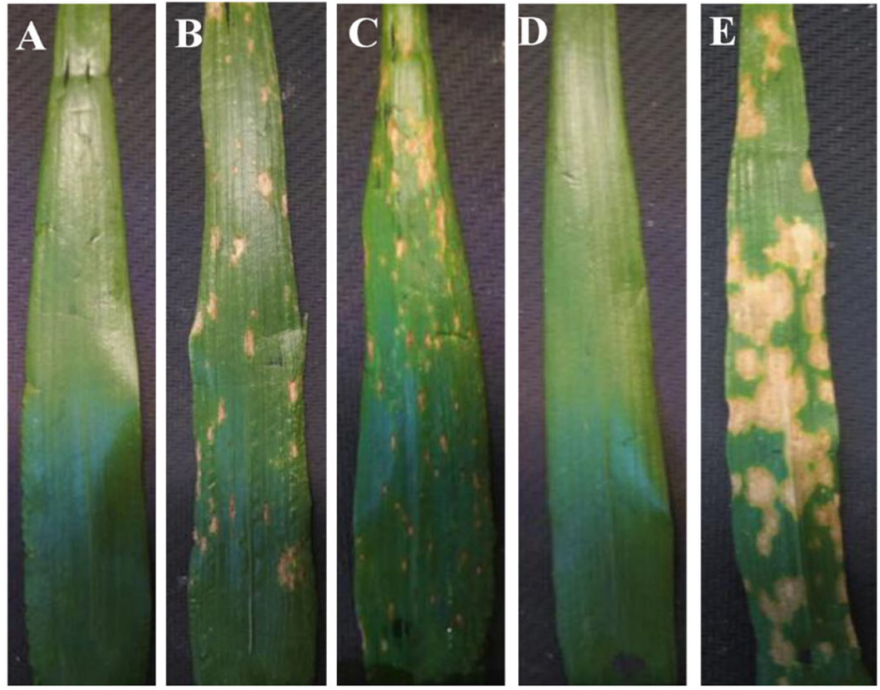

(b)

Fig. 3 Phenotype of spikes (a) and flag leaves (b) of $\operatorname{KD} 527(\mathbf{a})$ and $\operatorname{Impa1}(\mathbf{e})$ and the $F_{1}(\mathbf{b})$ and $F_{2}(\mathbf{c}$, d) offspring of $/ \mathrm{mpa} / \mathrm{KD} 527$ (bar $=2 \mathrm{~cm}$ ). Note :a: KD527, WT; b: Impa1/KD527 F1, Impa; c: Impa1/KD527 $F_{2}$ Impa; d: Impa1/KD527 $F_{2}$, WT; e: Impa1, Impa

brown-yellow round disease spots which can gradually enlarge and expand. After heading, the disease spots quickly spread to the leaf sheath, stem and spike of Impa1. With the extension of growth period, Impal emerges more and more disease spots over the whole plant and dried up even died during the filling stage (Fig. 2). In addition, the number of mutant individuals increases obviously after rain during grain filling and they get worse than before rain. The reason is unclear yet.

\section{Genetic analysis of Impa mutant}

In order to clarify the inheritance and genetic effects of the lmpa traits, the single plant lmpa traits and other agronomic traits of lmpa1, KD527 and CS crosses $\mathrm{F}_{1}$ and $F_{2}$ were investigated. The results were statistically shown in Tables 1 and 2.
As can be seen from Table 1 and Fig. 3, the KD527 plants behaved normally, Impa1 suffered from plaquelike premature aging. The plants of the constructed hybrid $F_{1}$ population all showed lesion-like premature senescence characters. The plants from the $F_{2}$ population showed two types of premature senescence plants and normal plants. Chi-square test showed that Lmpa1 gene is dominant and conforms to the separation ratio of single gene 3:1.

lmpa1 had shorter $e l$ and lower npge than that of KD527 (Table 2). The thousand grain weight (tgw) and yield per plant $(y p p)$ in $\mathrm{F}_{2}$ were significantly higher than those in lmpa plants, indicating that the mutant's earlylike traits could significantly reduce wheat yield. However, the reduction extent to which it causes wheat yield and whether it has other disease resistance still needs further identification. 


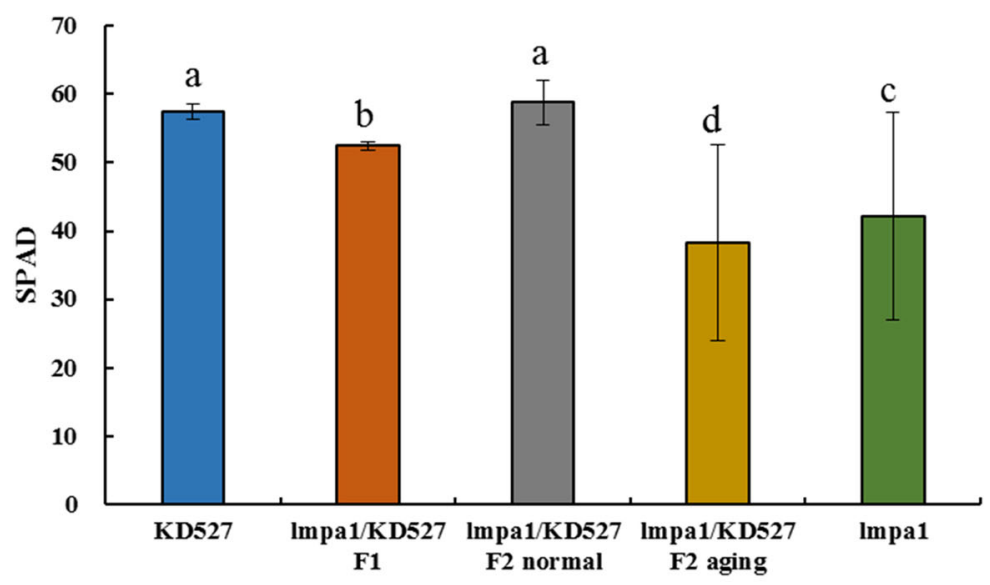

(A)

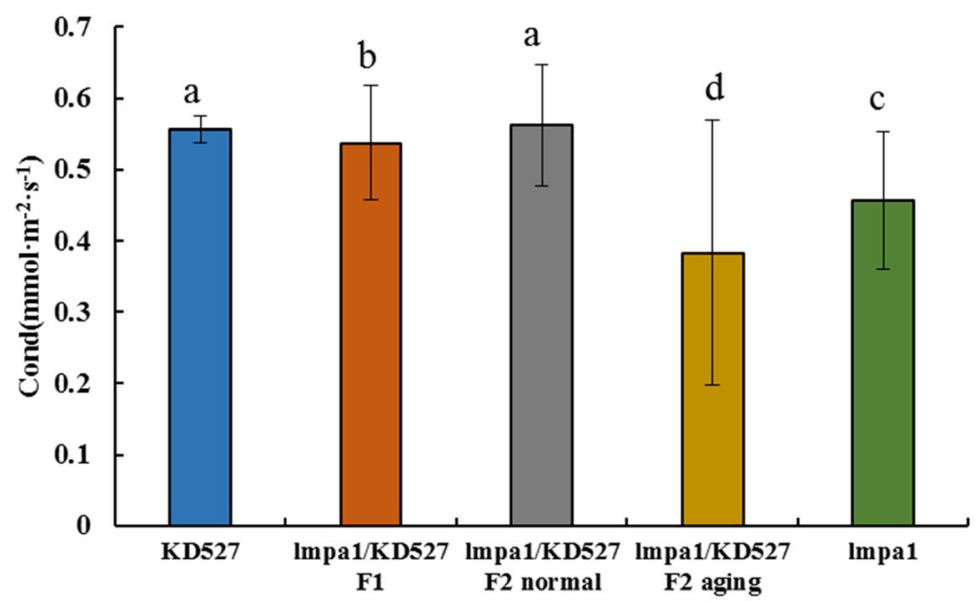

(B)

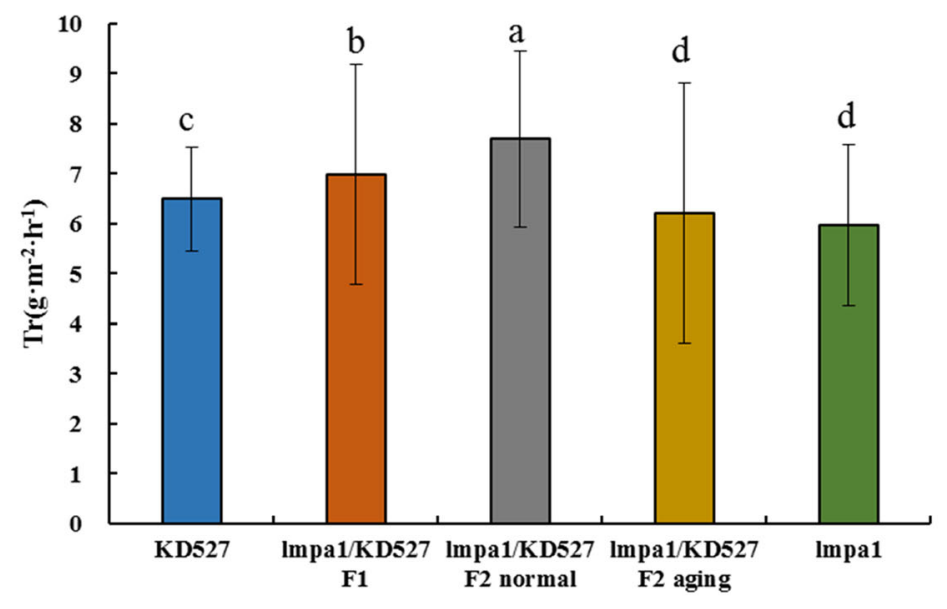

(C)

Fig. 4 Determination of photosynthetic physiological indexes of KD527 and Impal and their hybrids. Note:a: relative chlorophyll content (SPAD); b: stomatal conductance $\left(\mathrm{mmol} \cdot \mathrm{m}^{-2} \cdot \mathrm{s}^{-1}\right)$; c: transpiration rate $\left(\mathrm{g} \cdot \mathrm{m}^{-2} \cdot \mathrm{h}^{-1}\right) ; \mathbf{a}, \mathbf{b}, \mathbf{c}$ : significant difference at 0.05 level 


\section{Photosynthetic assay of Impa mutants}

In order to further understand the effects of mutants on wheat photosynthetic physiology, SPAD-502 Plus and LI$6400 X T$ were used to measure chlorophyll content (SPAD), stomatal conductance (Cond), and transpiration rate (Tr) of KD527, lmpa1, and their hybrids in the field (Fig. 4).

Physiological indicators comprising SPAD, Cond and Tr of lmpa1/KD527 $\mathrm{F}_{1}$ were higher than that of lmpa1. However, these indicators in normal plants from $F_{2}$ population were not significantly different from that of KD527 and were significantly higher than those of lmpa plants. It indicated that the Impa mutant had a significant effect on wheat photosynthetic physiological process. As a result, lmpal affected wheat growth and development so seriously that the plant cannot age normally and premature senescence occurs, which may also be one of the reasons for reducing the thousand grain weight of single plant in wheat.

\section{Chromosomal location of Lmpa1 gene}

DNA samples from CS, lmpa1, and mixed samples of normal plants (50) and premature senescent plants (50) in the $\mathrm{F}_{2}$ population of combination lmpa1/CS was used to construct a BSA pool for $660 \mathrm{~K} \mathrm{SNP}$ array analysis. As a result, 170 polymorphic SNP loci distributed on chromosomes $1 \mathrm{~A}, 2 \mathrm{~A}, 3 \mathrm{~B}, 4 \mathrm{~B}, 5 \mathrm{~A}, 5 \mathrm{~B}$ respectively were found (Fig. 5) and 164 SNP loci were located on chromosome 5A. It is presumed that the Lmpal gene is located on the $5 \mathrm{~A}$ chromosome of wheat. Based on physical positions of the polymorphic SNPs in Chinese Spring (IWGSCv2.0), a genetic linkage map of SNPs linked with Lmpa1 genes on chromosome 5A were constructed by MapChart (Fig. 6). The results showed that most of the polymorphic SNPs are enriched within a 30$40 \mathrm{Mb}$ region near to the short arm of chromosome $5 \mathrm{~A}$, indicating that the $L M P A 1$ gene is highly possible within this region.

\section{Screening of candidate genes related to Lmpa 1}

Based on the results of the $660 \mathrm{~K} \mathrm{SNP}$ chip, we used the website of JBrowse (http://202.194.139.32/jbrowse-1.12.3release $/$ ?data $=$ Chinese_Spring) to screen related genes in the $30-40 \mathrm{Mb}$ segment of the short arm of wheat $5 \mathrm{~A}$ chromosome. A total of 120 genes were found within the $30-40 \mathrm{Mb}$ region of chromosome 5A. And 13 genes related to plant growth and development may be the candidate genes associated with Lmpa1 (Table 3).

\section{Discussions}

Premature senescence is a phenomenon that aging of plants physiological and biochemical process in their growth period takes place earlier than that of normal plants. Premature senescence in cereal crops such as wheat, rice and corn, will affect the production of photosynthetic products and their transportation and accumulation into grains and in turn decrease grain yield. Premature aging mutants can be regarded as an important tool to understand premature senescence and benefit elucidating the PCD in plants. Precious researches on premature senescence mainly focus on rice premature senescence mutants and their gene mapping. There are few reports on the creation of wheat premature senescence mutants, the main ones are some types of leaf premature aging. For example, M.M.Li [39] developed 7 polymorphic markers linked to the early leaf senescence gene els1 by applying a large number of segregant analyses and RNA-Seq.

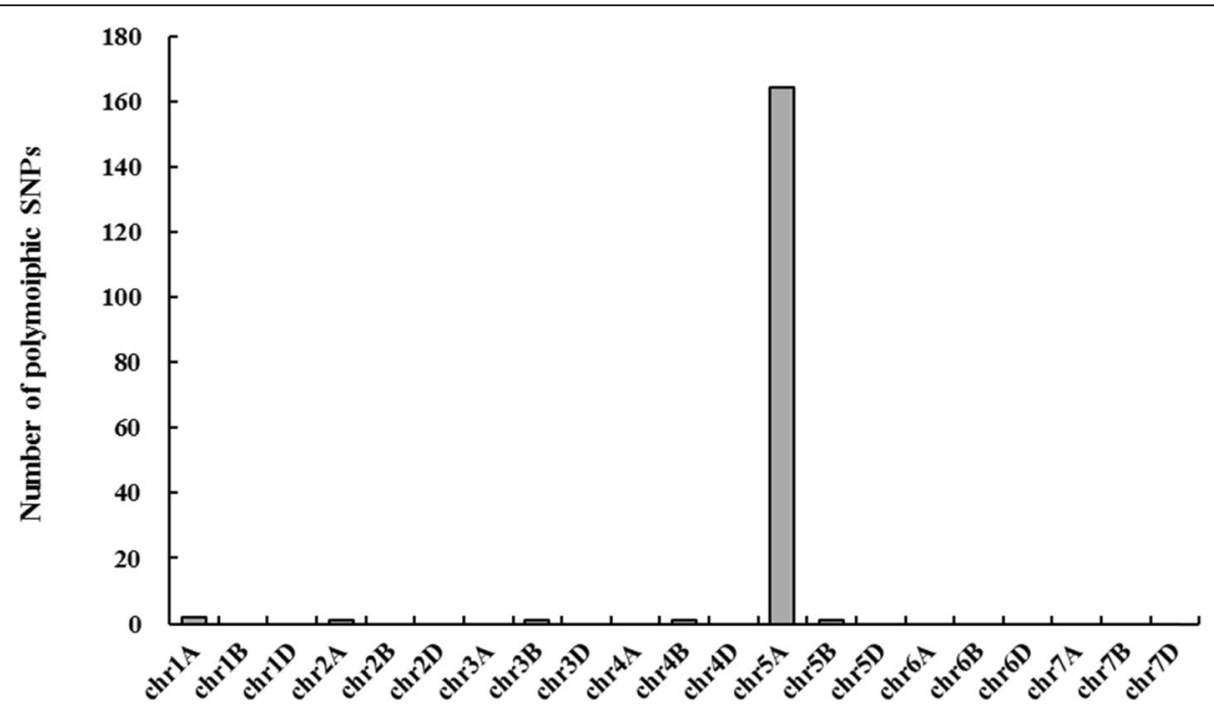

Fig. 5 Distribution of polymorphic SNPs on each chromosome 


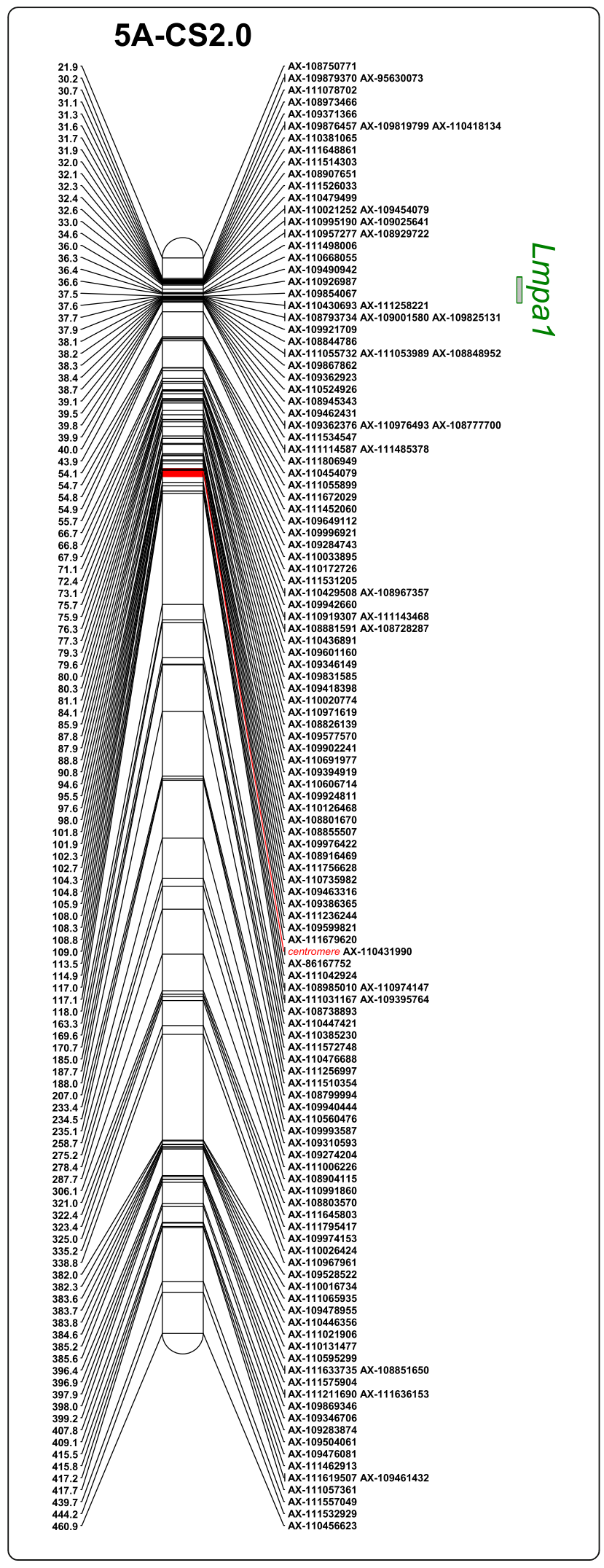

Fig. 6 Genetic linkage map of SNPs related to premature aging gene on chromosome 5A. Notes: The red segment indicates the estimated centromeric region. The rectange in green on the right of the chromosome indicates the estimated chromosomal region of the gene Lmpal

This study reports the lmpal mutant deriving from the EMS-induced mutant library in the KD527 background. The mutant with the characteristics of both lesion-like spots and premature senescence, will enrich the wheat premature senescence mutant library and lay the germplasm foundation for further research on the traits related to early senescence in wheat.

In this study, we characterized the mutants Impal and analyzed its photosynthetic physiology. We found that lesion-like spots and premature senescence can significantly affect $e l$, seed setting rate (ssr), tgw and other agronomic traits in wheat. They can reduce the expression of chlorophyll, cause the physiological dysfunction of leaves and decrease the ability of photosynthetic assimilation. As a result, the grain filling time was shortened, the dry matter accumulation of the grain was reduced, the $s s r$ and the $t g w$ were affected, and the yield and quality were damaged. In order to better understand the physiological and biochemical mechanisms of premature senescence, we will refer to B.F.Wang's [41] methods on premature aging mutants in rice. It is planned to use cell histochemical staining, determination of net photosynthetic rate and photosynthetic pigment content and determination of enzyme activity to find physiological and biochemical indicators related to senescence. In the meantime, cell morphology of mutants will be observed by transmission electron microscope. And the expression of gene related to senescence and hormone content in mutants will be analyzed. The differences in physiological and biochemical, hormone, and cell morphology between premature aging mutants and normal plants will be discussed. It has been reported that rice lesions-like mutant spl41 [42] can enhance resistance to rice bacterial leaf blight. Therefore, disease resistance of lmpal should be identified in the future.

In this study, the Lmpa1 was located within $30-40 \mathrm{Mb}$ region on chromosome $5 \mathrm{~A}$ by using of SNP chip sequencing and BSA analysis. Up to date, there is no report of premature aging gene on the chromosome $5 \mathrm{~A}$ in wheat. Among the 13 candidate genes, the candidate gene TraesCS5A01G040300.1 encoding a zinc finger protein is similar to the zinc finger transcription factor found in wheat leaf premature senescence mutant $m 68$ [43] and may be associated with premature aging. It is important to screen premature aging genes and explore the causes and mechanisms of premature aging. It was found [44] that water deficit during grain filling period could cause premature senescence of flag leaves, but the 
Table 3 List of Candidate Genes Related to Wheat Early Aging

\begin{tabular}{llll}
\hline Gene name & Gene annotation & Gene length (bp) & Protein length (aa) \\
\hline TraesCS5A01G034300.1 & Protein kinase superfamily protein & 1194 & 397 \\
TraesCS5A01G035200.1 & Protein kinase family proteins & 2346 & 781 \\
TraesCS5A01G037100.1 & Kinase family proteins & 1831 & 477 \\
TraesCS5A01G043600.1 & Protein kinase family proteins & 2148 & 715 \\
TraesCS5A01G038300.2 & Auxin response factor & 4008 & 899 \\
TraesCS5A01G039100.1 & peroxidase & 1250 & 340 \\
TraesCS5A01G039400.1 & peroxidase & 1129 & 277 \\
TraesCS5A01G039500.1 & peroxidase & 1400 & 340 \\
TraesCS5A01G040300.1 & Zinc finger protein & 1246 & 287 \\
TraesCS5A01G040500.1 & Remorin & 1800 & 449 \\
TraesCS5A01G041500.1 & Myb-related transcription factor & 390 & 309 \\
TraesCS5A01G041600.2 & Pentapeptide repeat superfamily protein & 1248 & 266 \\
TraesCS5A01G042500.1 & Protein TRIGALACTOSYLDIACYLGLYCEROL 2 & 1660 & 446
\end{tabular}

senescence process could be delayed by changing hormone concentration of plants. There are many reasons for rice premature aging, for example, the effect of NAC transcription factors on abscisic acid (ABA) [25], the functional impairment of calcium-dependent protein kinase OsCPK12 [28], the deletion of gene fragment [29], the response and regulation of genes related to antioxidant and carbohydrate metabolism [45], and so on. Based on the research experience of rice early senescence, further work should be focused on the cloning and functional verification of candidate gene for premature aging. The effects of premature aging on protein expression, hormone signaling pathways, and gene expressing related to metabolism, will be emphasized in order to further reveal the molecular mechanism of wheat premature senility.

\section{Conclusions}

We identified an EMS-mutagenized mutant lmpa1, which derived from elite wheat line KD527 and conferred lmpa. Genetic analysis indicated that the lmpa phenotype of lmpal mutant is controlled by a single dominant allele designated as Lmpa1, which affected wheat growth and development and reduced the tgw of single plant in wheat. By applying BSA method and 660 K SNP Chip sequencing, the gene Lmpa1 was tentatively located within the region of $30-40 \mathrm{Mb}$ near to the short arm of chromosome 5A.

\section{Methods and materials \\ Plant materials}

The materials for this study were the bred new wheat line KD527 (from our laboratory), the lmpal mutant (isolated from the EMS mutant library of KD527), the $\mathrm{F}_{1}$ and $F_{2}$ hybrid populations of lmpa1 and KD527, and lmpa1 and $F_{1}$ and $F_{2}$ populations crossed by CS. All materials from the Wheat Germplasm Innovation Group of the Henan University of Science and Technology are maintained and planted in Luoyang City, Henan Province, China.

\section{EMS mutagenesis}

Seeds were soaked with distilled, deionized water at room temperature for $16 \sim 20 \mathrm{~h}$ until seeds completely absorb water and fully swell. Seeds were then treated with $0.3 \%$ EMS in phosphate buffer, $\mathrm{pH} 7$ at room temperature for $4 \sim 6 \mathrm{~h}$. The treated seeds were then rinsed in tap water for $12 \mathrm{~h}$, dried for 30mins, and immediately sown in the field.

\section{Screening of Impa mutants}

EMS-mutagenized KD527 seeds were grown with row spacing of $20 \mathrm{~cm}$ and plant spacing of $5 \mathrm{~cm}$. Individual plants with lesion-like spots were identified from the $\mathrm{M}_{0}$ population materials and harvested as $M_{1}$. In the second year, $M_{1}$ seeds were grown in the field, evaluated for their agronomic traits during growth, and harvested as a single plant as $\mathrm{M}_{2} . \mathrm{M}_{2}$ were planted and evaluated on the stability of mutant traits during their growth. From $\mathrm{M}_{3}$ generation on, field investigation was conducted every 7 days. Ten plants were randomly selected from typical mutant lines. The plant height $(p h)$, plant spike number $(p p n)$, panicle length $(p l)$, panicle grain number $(p g n)$ and other agronomic traits were investigated and evaluated. All stable mutant individuals were harvested and threshed to survey ear length $(e l)$, thousand-grain weight $(t g w)$, yield per plant (ypp) and other seed traits. The agronomy identification and stability evaluation were carried out continuously in $\mathrm{M}_{4}$ and $\mathrm{M}_{5}$ 
generations. Finally, the stable mutant lmpal was bred in $\mathrm{M}_{6}$ generation.

\section{Construction of segregating population of premature senescence mutants}

lmpa1 was first crossed with KD527. The $\mathrm{F}_{1}$ seeds were harvested on a single plant basis and were planted in the field to investigate the lesion-like spot premature senescence trait and other agronomic traits during the growing period. They were harvested as $F_{2}$ seeds. The lesionlike spot premature senescence trait and other agronomic traits of the individual plants in $\mathrm{F}_{2}$ population were also investigated to determine the genetic mode and genetic effect of the $L M P A$ gene.

lmpa1 was also crossed with CS as described above. Based on the lesion-like spot premature senescence trait of the $F_{2}$ population, the leaf DNA samples of typical Lmpa and normal individual plants were extracted and combined as a BSA pool for the $660 \mathrm{~K}$ SNP array sequencing analysis to locate $L M P A$ gene to specific chromosome. DNA extraction from leaves was performed according to the methods described by Y. Wang et al. [46].

\section{Measurement of chlorophyll content and photosynthesis activities}

After wheat heading, the chlorophyll content and photosynthesis activities of lmpa1, KD527 and their hybrid $\mathrm{F}_{1}$ and $\mathrm{F}_{2}$ populations were measured by using chlorophyll meter SPAD-502Plu (Konica Minolta, Japan) and portable photosynthesis meter LI-6400 XT (LI-COR, American) on May 1st and May 18th, 2019, respectively. The measurement methods were strictly in accordance with the operation manuals.

\section{Chromosomal location analysis}

Fifty typical lmpa plants and 50 normal plants selected from the lmpa1 x CS $F_{2}$ population were combined respectively into two DNA BSA pools marked lmpa pool (LP) and normal pool (WT). The $660 \mathrm{~K} \mathrm{SNP} \mathrm{chip} \mathrm{ana-}$ lysis was conducted by Zhongyujin Label Biotechnology Co., Ltd. in Beijing, China. Using the DNA pools of CS and lmpa 1 as controls, the candidate chromosome segments were estimated by screening significant differences in allele frequencies (AF) of polymorphic sites (SNPs) between the two BSA pools of LP and WT respectively.

\footnotetext{
Abbreviations

Lmpa: Lesion-mimic and premature aging; EMS: Ethyl methane sulfonate; KD527: Keda 527; BSA: Bulked segregation analysis; CS: Chinese spring; WT: Wild type; tgw: Thousand grain weight; IIm: Lesion-like mutants; PCD: Programmed cell death; BSR-Seq: Bulked segregant RNA sequencing; ph: Plant height; fll: Flag leaf length; el: Ear length; ngpe: Number of grains per ear; ypp: Yield per plant; Cond: Stomatal conductance; Tr: Transpiration rate; ssr: Seed setting rate; $A B A$ : Abscisic acid; $p p n$ : Plant spike number;
}

pl: Panicle length; pgn: Panicle grain number; LP: Lmpa pool; AF: Allele frequencies; SNPs: Single nucleotide polymorphism sites

\section{Acknowledgments}

We thank Dr. Fa Cui from Ludong University for his guidance and help in mapping and thank Dr. Zhongguo Xiong from Arizona University of the United States of America for providing language help of writing manuscript.

\section{Authors' contributions}

WL and SJ designed the research project; KW and WL performed the experiments and wrote the manuscritpt; JJ, YX and DP performed the experiments and managed experimental materials in the field; KW, LX and WC analyzed the data; WL and SJ edited paper; WL, CP and WH provide funding. All authors have read and approved the final manuscript.

\section{Funding}

This work was financially supported by the National Natural Science Foundation of China-Henan Joint fund (U1304318, U1904108) and Scientific and technological projects of Henan Province of China (202102110022). The funding bodies played no role in the design of the study and collection, analysis, and interpretation of data and in writing the manuscript.

\section{Availability of data and materials}

The data sets supporting the results of this article are included in this manuscript. The datasets generated and/or analysed during the current study are available in the http://plants.ensembl.org/Triticum_aestivum/Tools/ Blast? $\mathrm{db}=$ core.

Ethics approval and consent to participate

Not applicable.

\section{Consent for publication}

Not applicable.

\section{Competing interests}

The authors declare no competing or financial interests.

\section{Author details}

${ }^{1}$ Agronomy College, Henan University of Science and Technology, Luoyang 471023, Henan, China. ${ }^{2}$ Institute of Botany, Chinese Academy of Sciences, Beijing 10093, China. ${ }^{3}$ State Key Laboratory of Crop Biology/Agronomy College, Shandong Agricultrual University, Taian 271018, Shandong, China. ${ }^{4}$ Institute of Crop Science, Chinese Academy of Agricultural Sciences, Beijing 10081, China.

Received: 26 April 2020 Accepted: 20 July 2020

Published online: 17 August 2020

References

1. Johal GS, Hulbert SH, Briggs SP. Disease lesion mimics of maize: a model for cell death in plants. Bioessays. 2010:685-92 https://doi.org/10.1002/bies. 950170805 .

2. Dangl JL, Dietrich RA, Richberg MH. Death don't have no mercy: cell death programs in plant-microbe interactions. Plant Cell. 1996:1793-807 https:// doi.org/10.1105/tpc.8.10.1793.

3. Zhong ZQ, Luo WL, Liu YZ, Wang H, Chen ZQ, Guo T. Characterization of a novel spotted leaf mutant spl32 and mapping of spl32(t) gene in rice (Oryza sativa). Acta Agron Sin. 2015:861-71 https://doi.org/10.3724/SP.J.1006.2015. 00861.

4. Xiao G, Zhang Y, Yang BN, Liu BC, Zhou JH, Zhang HW. Research progress of plant lesion mimic mutants. Mol Plant Breed. 2017:300-9 https://doi.org/ 10.13271/j.mpb.015.000290.

5. Ma HP, Zhao HP, Yang G. Application of induced mutation technology for crop breeding. Hereditas (Beijing). 1998:50-2 https://doi.org/10.16288/j.yczz. 1998.04.014.

6. Zhu BG, Lu ZX, Geng YX, Deng XD, Gu AQ. Effects of peanut character variations induced by EMS and breeding of high yielding mutant strains. Sci Agric Sin. 1997:87-9 https://doi.org/10.1007/BF02951625.

7. Zhang ZC, Dai S, Cheng DG, Peng Q, Xing YX, Song JM. Effect of EMS mutagenesis on physico-chemical properties of wheat starch. J Southern Agric. 2011:479-82 https://doi.org/10.3969/j.issn.2095-1191.2011.05.005. 
8. Amberg DC, Burke DJ, Strathern JN. Ethyl methane sulfonate (EMS) mutagenesis. Csh Protocols. 2006;4180 https://doi.org/10.1101/pdb.prot4180.

9. Joanna JC, Bradley JT. Chemical mutagenesis of seed and vegetatively propagated plants using EMS. Curr Protocols Plant Biol. 2016:617-35 https:// doi.org/10.1002/cppb.20040.

10. Qian Y. Identification of mutant traits in wheat induced by EMS. Shandong: Shandong Agricultural University; 2017.

11. Gray J, Close PS, Briggs SP, Johal GS. A novel suppressor of cell death in plants encoded by the LIs1 gene of maize. Cell. 1997:25-30 https://doi.org/ 10.1016/S0092-8674(00)80179-8.

12. Guo CY, Wu GH, Xing J, Li WQ, Tang DZ, Cui BM. A mutation in a coproporphyrinogen III oxidase gene confers growth inhibition, enhanced powdery mildew resistance and powdery mildew-induced cell death in arabidopsis. Plant Cell Rep. 2013:687-702 https://doi.org/10.1007/s00299013-1403-8.

13. Zhang $X Q$, Tian B, Fang $Y X$, Tong T, Zheng JJ, Xue DW. Proteome analysis and phenotypic characterization of the lesion mimic mutant bspl in barley. Plant Growth Regul. 2019:329-39 https://doi.org/10.1007/ s10725-018-00474-y.

14. Jiao R, Xu N, Hu J, Song ZL, Hu JQ, Rao YC, Wang YX. Advances in traits of lesion mimic mutants and its molecular mechanisms in rice. Chin J Rice Sci. 2018:285-95 https://doi.org/10.16819/j.1001-7216.2018.7153.

15. Geng JF. Fine mapping of wheat disease-like spot mutation gene $/ \mathrm{m} 3$. Yangling: Northwest A \& F University; 2018.

16. Li QQ, Zhao QS, Jiang HB, Geng JF, Liu LX, Zhang XY, Xie YZ, Wang CS. Characteristics and genetic analysis of wheat mutant 130 with white stripe pattern. J Triticeae. Crops. 2017:871-9 https://doi.org/10.7606/j.issn.10091041.2017.07.03

17. Yao Q, Zhou RH, Fu TH, Wu WR, Zhu ZD, Li AL, Jia JZ. Characterization and mapping of complementary lesion-mimic genes $/ \mathrm{m} 1$ and $/ \mathrm{m} 2$ in common wheat. Theor Appl Genet. 2009:1005-12 https://doi.org/10.1007/s00122-0091104-4.

18. Kinane JT, Jones PW. Isolation of wheat mutants with increased resistance to powdery mildew from small induced variant populations. Euphytica. 2001;117(3):251-60.

19. Nair SK, SmsT. Genetical and anatomical analyses of a leaf flecking mutant in Triticum aestivum L. Euphytica. 2001;121(1):53-8.

20. Luo PG, Ren ZL. Wheat leaf chlorosis controlled by a single recessive gene. J Plant Physiol Mol Biol. 2006;32(3):330-8.

21. Li T, Bai GH. Lesion mimic associates with adult plant resistance to leaf rust infection in wheat. Theor Appl Genet. 2009;119(1):13-21.

22. Kamlofski CA, Antonelli E, Bender C, Jaskelioff M. Acevedo A. A lesion-mimic mutant of wheat with enhanced resistance to leaf rust. Plant Pathol. 2010; 56(1):46-54.

23. Du LF, Li MF, Liu LX, Wang CJ, Liu Y, Xu XT, Zou SF, Xie YZ, Wang CS. Physiological Characteristics and Genetic Analysis on a Spotted-leaf Wheat Derived from Chemical Mutation. Acta Agron Sin. 2014;40(6):1020-6.

24. Chen CR, Wu YJ, Wang ZL, Wang YP, Liu SD, Wang XB. Characteristics of stay-green and grain-filling and the evaluation of anti-senescence properties of winter wheat. Acta Botan Boreali-Occiden Sin. 2011:715-23 https://www. doc88.com/p-7099532245728.html.

25. Mao CJ, Lu SC, Lv B, Zhang B, Shen JB, He JM, Luo LQ, Xi DD, Chen X, Ming $F$. A rice NAC transcription factor promotes leaf senescence via $A B A$ biosynthesis. Plant Physiol. 2017:1747-63 https://doi.org/10.1104/pp.17. 00542.

26. He Y, Li LJ, Zhang ZH, Wu JL. Identification and comparative analysis of premature senescence leaf mutants in rice (Oryza sativa L.). Int J Mol Sci. 2018:140-57 https://doi.org/10.3390/ijms19010140.

27. Xu FF, Ji ZY, Xu JM, Wang FJ, Tang YC, Zheng KL, Wang CL, Zhao KJ. Identification and molecular mapping of water-soaked spot leaf early senescence mutant wss1 in rice. J Plant Genet Res. 2019:144-51 https://doi. org/10.13430/j.cnki.jpgr.20181223002.

28. Wang BF, Zhang YX, Bi ZZ, Liu QN, Xu TT, Yu N, Cao YR, Zhu AK, Wu WX, Zhan XD, Anis GB, Yu P, Chen DB, Cheng SH, Cao LY. Impaired function of the calcium-dependent protein kinase, OSCPK12, leads to early senescence in rice (Oryza sativa L.). Front Plant Sci. 2019:1-12 https://doi.org/10.3389/ fpls.2019.00052.

29. Zhao CY, Liu CL, Zhang Y, Cui YT, Hu HT, Jahan N, LV Y, Qian Q, Guo LB. A 3-bp deletion of WLS5, gene leads to weak growth and early leaf senescence in rice. Rice. 2019:1-13 https://doi.org/10.1186/s12284-0190288-8.
30. Xu FF, Sang XC, Ren DY, Tang YQ, Hu HW, Yang ZG, Zhao FM, He GH. Genetic analysis and gene mapping of early senescence leaf mutant es/2 in rice. Acta Agron Sin. 2012:1347-53 https://doi.org/10.3724/SP.J.1006.2012. 01347.

31. Miao RL, Jiang YD, Liao HX, Xu FF, He GH, Yang ZG, Zhao FM, Sang XC. Identification and gene mapping of rice early senescent leaf (es/3) mutant. Acta Agron Sin. 2013:862-7 https://doi.org/10.3724/SP.J.1006.2013.00862.

32. Guo $S$, Zhang $T Q$, Xing $Y D$, Zhu $X Y$, Sang $X C$, Ling $Y H$, Wang $N, H e ~ G H$. Identification and gene mapping of an early senescence leaf 4 mutant of rice. Crop Sci. 2014:2713-23 https://doi.org/10.2135/cropsci2013.12.0854.

33. Sang XC, Xu FF, Zhu XY, Xing YD, He PL, Zhang CW, Yang ZL, He GH. Identification and gene fine mapping of early senescent leaf mutant es/5 in oryza sativa. https://doi.org/10.3724/SP.J.1006.2014.01182.

34. Yang B, Xia M, Zhang XB, Wang XW, Zhu XY, He PL, He GH, Sang XC. Identification and gene mapping of an early senescent leaf mutant es/6 in oryza sativa L. Acta Agron Sin. 2016:976-83 https://doi.org/10.3724/SP.J. 1006.2016.00976.

35. Xiao LJ, Huang J, Cao PH, Mou C, Nguyen T, Liu SJ, Chen LM, Jiang L. Analysis and gene mapping of rice premature senescence mutant zs. Nanjing Agric Univ. 2018:793-800 https://doi.org/10.7685/jnau.201802016.

36. Wang M, Zhang T, Peng H, Luo S, Tan JJ, Jiang KF, Heng YQ, Zhang X, GuoXP ZJK, Cheng ZJ. Rice premature leaf senescence 2, encoding a glycosyltransferase (GT), is involved in leaf senescence. Front Plant Sci. 2018: 560-73 https://doi.org/10.3389/fpls.2018.00560.

37. Wei XY, Li SS, Jiang FS, Guo Y, Li RJ. QTL mapping for premature senescence and related physiological traits in wheat. Acta Botan BorealiOcciden Sin. 2007:485-9 https://doi.org/10.3321/j.issn:1000-4025.2007.03.011.

38. Wu HQ, Liu TX, Li TT, Zhao P, Li CL, Wang ZH, Quan L. QTL mapping for early aging of flag leaf in wheat. Acta Botan Boreali-Occiden Sin. 2016:19627 https://doi.org/10.7606/j.issn.1000-4025.2016.10.1962.

39. Li MM, Li BB, Guo GH, Chen YX, Xie JZ, Lu P, Wu QH, Zhang DY, Zhang HZ, Yang JY, Zhang PP, Zhang Y, Liu ZY. Mapping a leaf senescence gene els1 by BSR-Seq in common wheat. Crop J. 2018:236-43 https://doi.org/10.1016/ j.cj.2018.01.004.

40. Kajimura T, Mizuno N, Takumi S. Utility of leaf senescence-associated gene homologs as developmental markers in common wheat. Plant Physiol Biochem. 2010:48(10-11):851-9.

41. Wang BF, Chen YY, Zhang YX, Liu QE, Sun B, Xiang XJ, Cao YR, Cheng SH, Cao LY. Identification and fine mapping of an early senescent leaf mutant es5 in oryza sativa L. Sci Agric Sin. 2018:613-25 https://doi.org/10.3864/j.issn. 0578-1752.2018.04.002.

42. Ren YJ, Zhu BG, Tao J, He CZ, Niu XL. Phenotypic and physiological analysis of a rice lesion mimic mutant sp/41. Mol Plant Breed. 2020:1-14 https://doi. org/10.13271/j.mpb.018.001967.

43. Zhang Q, Xia C, Zhang LC, Dong CH, Liu X, Kong XY. Transcriptome analysis of a premature leaf senescence mutant of common wheat (Triticum aestivum L.). Int J Mol Sci. 2018:782-800 https://doi.org/10.3390/ ijms19030782.

44. Luo YL, Pang DW, Jin M, Chen J, Kong X, Li WQ, Chang YL, Li Y, Wang ZL. Identification of plant hormones and candidate hub genes regulating flag leaf senescence in wheat response to water deficit stress at the grain-filling stage. Plant Direct. 2019:1-23 https://doi.org/10.1002/pld3.152.

45. Li ZW, Pan XF, Guo XD, Fan K, Lin WX. Physiological and transcriptome analyses of early leaf senescence for ospls 1 mutant rice (Oryza sativa L.) during the grain-filling stage. Int J Mol Sci. 2019:1-22 https://doi.org/10. 3390/ijms20051098.

46. Wang $Y$, Zhang HZ, Xie JZ, Guo BM, Chen YX, Zhang HY, Lu P, Wu QH, Li MM, Zhang DY, Guo GH, Yang J, Zhang PP, Zhang Y, Wang XC, Zhao H, Cao TJ, Liu ZY. Mapping stripe rust resistance genes by BSRSeq:YrMM58 and YrHY1 on chromosome 2AS in Chinese wheat lines Mengmai 58 and Huaiyang 1 are Yr17. Crop J. 2018:91-8 https://doi. org/10.1016/j.cj.2017.03.002.

\section{Publisher's Note}

Springer Nature remains neutral with regard to jurisdictional claims in published maps and institutional affiliations. 